\title{
Education and subjective well-being. Observations from Madagascar
}

\begin{abstract}
This paper examines the association between education and subjective well-being (SWB). To this end, the data collected during the My Baobab Foundation's (FMB) operations in Madagascar in 2007-2020 are analyzed a posteriori. The paper offers some insight into what is required for a lowincome country to follow the pathway to education, and examines how educational efforts can translate into an improvement in SWB.
\end{abstract}

Keywords

Subjective well-being $(\mathrm{SWB}) \cdot$ education $・$ developing countries $\bullet$ Madagascar

(C) University of Warsaw - Faculty of Geography and Regional Studies
Małgorzata Klein (두

Faculty of Geography and Regional Studies,

University of Warsaw, Warsaw, Poland

e-mail: malgorzata.klein@uw.edu.pl

Received: 22 April 2020

Accepted: 2 March 2021
"Happiness can also be here."

\section{Introduction}

This paper examines the impact of education on subjective well-being (SWB) in developing countries. These regions have attracted a paucity of research in this area, despite being most in need of it, and the results of what few studies have been conducted are equivocal and inconclusive. Moreover, now that the world is moving forward with the UN Sustainable Development Goals' agenda to bring an end to poverty, the impact of education (which, together with income and health, has always been one of the three main determinants of development) on SWB - a relatively new but very pertinent indicator of progress - is all the more worthy of a deepened analysis. The present research is based on an a posteriori analysis of data collected during the My Baobab Foundation's (FMB) ${ }^{2}$ operations in Madagascar. These data have been analyzed to ascertain whether education can improve SWB in low-income countries, irrespective of whether people's main expectations are fulfilled, or whether there is any payoff in monetary terms.

\section{Theoretical framework}

Subjective well-being (SWB) studies first appeared in psychological research in the 1920s and have since spread to many other sciences. In conjunction with objective indicators, SWB is increasingly used to gauge the effects of developmental change, as discussing development and growth, shifts the focus from per capita GDP to happiness and life satisfaction (Stiglitz 2010).

As for the scarcity of research concerning the association between education and SWB, a very pertinent report entitled Education, Happiness and Well-being by A. Michalos (2007) provides a straightforward answer to the question of whether

${ }^{1}$ This is what the principal of an Ivorian school told his students after one of them had died on January 8, 2020 while trying to get to Europe in the undercarriage of an aircraft.

${ }^{2}$ The My Baobab Foundation's main program consists of granting university scholarships to Malagasy students who study in Madagascar. The program began in 2007 and has benefited 59 students as at the time of writing. education can influence happiness, and if so, in what way(s), and to what extent. The key to answering this question, according to the author, lies in using appropriate definitions for the basic terms "education," "influences," and "happiness." Once this has been done, it is obvious, he claims, that education has an enormous influence on SWB. The definition of "education" needs to be expanded to include non-formal education, selfstudy, professional training, and even social interactions and extraordinary life experiences. Similarly, the term "influence" needs to be understood more broadly than as a direct and positive correlation. Finally, "happiness" is defined as eudaimonia, and is not used in the more modern sense of "pleasure."

The terms "happiness" and "subjective well-being" are commonly used interchangeably. As defined by Diener et al. (2009), SWB encompasses a person's affective and cognitive evaluations of life. Happiness focuses more on how events are assessed as they occur and in the light of the moods and emotions they invoke, while SWB focuses more on life satisfaction and personal fulfillment.

In the growing body of research on SWB in developing countries (Gough et al. 2007; Pettit \& White 2004), publications that are focused principally on the correlation between education and SWB are difficult to find (Nilsson 2019), although efforts at the national level are worth noting (Akyeampong 2007; Botha 2014). A bivariate analysis is emphatically not recommended because SWB is multivariate by nature, and this could lead to spurious correlations. However, the correlation between the two variables invites research to determine all aspects of their ambiguous relation, especially in low-income countries.

Education was examined in a 2008 study by Howell and Howell that focused on the correlation between economic status and SWB. Having synthesized the findings of 111 independent samples from 54 economically developing countries, the authors concluded that "economic status is most strongly associated with SWB when educational attainment is rare (e.g. samples are poor) and individuals live in low-income developing countries." SWB is more strongly affected by income when people live at or around the threshold of fulfilling their physiological needs. The higher 
Table 1. The association between education and SWB, and the psychological dimension

\begin{tabular}{|c|c|c|}
\hline Term & Context & Source \\
\hline Expectations & $\begin{array}{c}\text { "education may improve well-being only if expectations are exceeded, but may } \\
\text { decrease well-being if they are not met }(\ldots) "\end{array}$ & $\begin{array}{l}\text { Kristoffersen } 2018 \\
\quad \text { p. } 66\end{array}$ \\
\hline Aspirations & $\begin{array}{l}\text { "education leads to both higher reported happiness and desired happiness. This } \\
\text { suggests that a significant part of the happiness effect of education is cancelled out } \\
\text { by higher aspirations: education then does raise actual happiness but also raises } \\
\text { expectations or aspirations about what the individual should receive (...)" }\end{array}$ & $\begin{array}{l}\text { Clark et al. } 2015 \text {, } \\
\quad \text { p. } 527\end{array}$ \\
\hline $\begin{array}{l}\text { Higher-level need } \\
\text { fulfillment }\end{array}$ & $\begin{array}{l}\text { "higher-level need fulfillment is perceived to be more important and bears more } \\
\text { strongly on SWB in wealthier samples than in poorer ones" }\end{array}$ & $\begin{array}{l}\text { Howell and Howell } \\
2008 \text {, p. } 555\end{array}$ \\
\hline Opportunity & $\begin{array}{c}\text { "[p]eople may dislike inequality if they suffer from it, or when they consider incomes } \\
\text { are not based on merits, but could be more tolerant if they have prospects of } \\
\text { improving their life conditions }(\ldots) "\end{array}$ & $\begin{array}{l}\text { García-Muñoz et al. } \\
\text { 2019, p. } 2\end{array}$ \\
\hline $\begin{array}{l}\text { Self-determination } \\
\text { theory (psychological } \\
\text { needs fulfillment) }\end{array}$ & $\begin{array}{l}\text { "the needs for competence }(\ldots) \text {, relatedness }(\ldots) \text {, and autonomy }(\ldots) \text { appear to be } \\
\text { essential for facilitating optimal functioning of the natural propensities for growth and } \\
\text { integration, as well as for constructive social development and personal well-being." }\end{array}$ & $\begin{array}{l}\text { Ryan and Deci } \\
2000 \text {, p. } 68\end{array}$ \\
\hline $\begin{array}{l}\text { Absolute/relative } \\
\text { economic status }\end{array}$ & $\begin{array}{c}\text { "for wealthier individuals, SWB is impacted by relative economic status }(\ldots) \text { rather } \\
\text { than absolute economic status }(\ldots) \text { " }\end{array}$ & $\begin{array}{l}\text { Howell and Howell } \\
2008 \text {, p. } 537\end{array}$ \\
\hline $\begin{array}{l}\text { Perception of living } \\
\text { conditions }\end{array}$ & $\begin{array}{c}\text { "People's perceptions, thoughts, feelings, and actions }(\ldots) \text { have an impact on their } \\
\text { own and others' living conditions." }\end{array}$ & Michalos 2007, p. 4 \\
\hline
\end{tabular}

Source: own elaboration

they are above this threshold, the less significant the impact of income becomes.

The impact of education on SWB was also examined in an impressive study by Reyes-García et al. (2016). The study sample comprised 6,973 rural households in 23 developing countries from Asia, Africa, and Latin America with an average annual per capita adult income of USD 1555.00. As with the Howell and Howell (2008) study, their main focus was on the correlation between income and SWB. They found no clear correlation between education level and SWB among the respondents. They further established that SWB in developing countries is indeed determined by multiple correlates, and that higher absolute income certainly impacts SWB in a positive way.

Apart from income level, psychological factors seem to significantly alter the relationship between education and SWB. Given the plethora of approaches, I have chosen the umbrellaterm "psychological dimension" to capture the multitude of facets. Table 1, above, lists the terms that reflect these different approaches.

According to Kristoffersen (2018), expectations play a crucial role in discerning the correlation between education and SWB, as "education may improve well-being only if expectations are exceeded, but may decrease well-being if they are not met." He also cites Clark et al. (2015), who were studying aspiration using Japanese survey data. These authors found that the "effect of education on subjective well-being is cancelled out by increases in aspirations." They remarked that the better educated will possibly be "hurt more" by a lack of success (i.e. "having less") than the less educated.

Even though Kristoffersen (2018) analyzed data from Australia and cited results from Japan, the Jiménez et al. study (2014), which focused on the European Social Survey's data, arrives at similar conclusions regarding the possible negative impacts of education on SWB.

Another approach within the psychological dimension is centered around opportunities, and can be found in, for example, García-Muñoz et al. (2019). These authors based their research on the World Value Survey's data for a group of 25 low- and middleincome countries, with the main focus on income inequality and the role of opportunity in life satisfaction. Their findings showed that the lower the number of opportunities, the more income inequality reduced well-being, while the greater the opportunities, the less relevant inequality was to life satisfaction. ${ }^{3}$ Interestingly, they also found that "inclusiveness and access to higher education play a more major role than political freedom or personal rights" when it comes to building a sense of opportunity. Higher education is expected to play a major role in creating a better life, even though the rate of failure in fulfilling this promise is high, especially in lowincome countries (e.g. in 2017, unemployment among those with higher education in Ivory Coast was $12.3 \%$ compared to $3.3 \%$ total unemployment). ${ }^{4}$

Michalos (2007) includes the four scenarios (in a simplified form) presented in Figure 1. They form an accessible tool in helping to understand the dynamics occurring between living conditions and how they are perceived. The following matrix sheds light on the discrepancies between a country's position in objective (e.g. HDI, SPI) versus subjective (e.g. World Happiness Index) rankings.

The psychological dimension and income level are closely related, and are essential in analyzing the relationship between education and SWB. Howell and Howell (2008) invoked the selfdetermination theory ${ }^{5}$ to explain the relevance and significance of fulfilling physiological needs to achieving SWB in low-income countries. However, although they stated that "higher-level need fulfillment is perceived to be more important and bears more strongly on SWB in wealthier samples than in poorer ones," they still called for further research on whether psychological need fulfillment can improve SWB in impoverished nations (Howell \& Howell 2008, p. 555). The present paper answers this very call.

\section{Study area and methods}

${ }^{3}$ Both terms as used in the cited research.

${ }^{4}$ All statistics are from the World Bank unless otherwise indicated. 


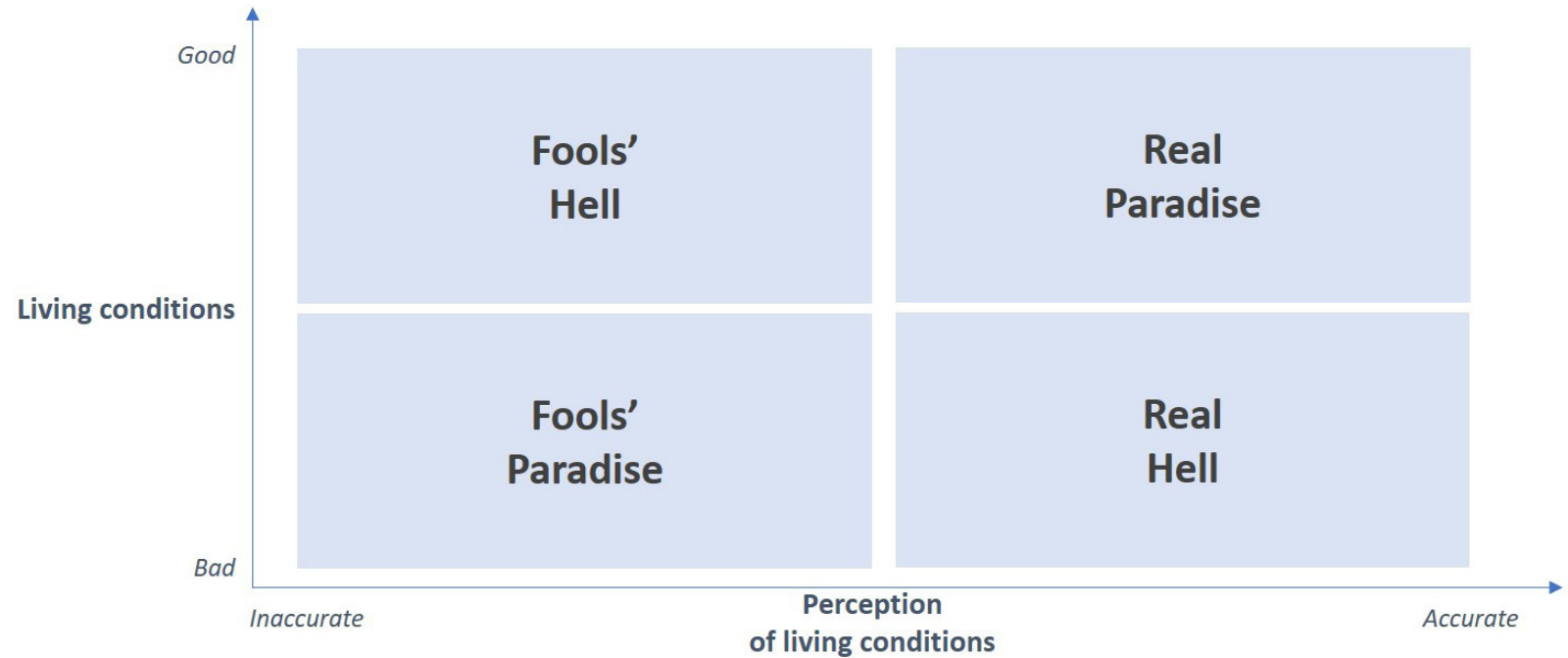

Figure 1. Michalos' living conditions matrix

Source: own elaboration based on Michalos (2007)

The fact that education is Madagascar's strongest HDI (Human Development Index) component makes this an interesting country in which to study the impact of education on SWB. ${ }^{6}$ Malagasy choose to go to (and stay in) school more often than their income level would lead one to believe (Malagasy pay to go to school; more on this in the Results section). The students supported by the My Baobab Foundation (FMB) come from the following areas: Antsirabe -2 students, Betafo -18 , Fianarantsoa - 12, Ivato - 3, Mahajanga - 7, Manazary - 8, Antananarivo -7 , and Toliara -2 . The students selected for the scholarship program have two major characteristics: first, they are top of their class, and second, their families cannot afford to send them to college. They find out about the program through Salesian schools, ${ }^{7}$ or through word of mouth. In Madagascar, preselection is carried out by the Salesian nuns and priests, and the selected students are then accepted or rejected by the Foundation's board in Poland, taking into account whether the yearly budget allows for the given number of new students.

\section{Well-being in Madagascar: Objective indicators}

The average Malagasy earns USD 4.50 a day, which places the population at Level 2 (USD 2-8/day) according to the Rosling Income Levels scale (Rosling 2018). Obviously, many people are at Level 1 (up to USD 2/day), as Madagascar has one of the world's lowest per capita incomes. For the year 2018, it ranked 176th out of 187 countries in GDP per capita, 161st out of 189 countries in $\mathrm{HDI}$, and 132nd out of 146 countries in the Social Progress Index.

\section{Well-being in Madagascar: Subjective indicators}

Madagascar is ranked 143rd out of 156 countries on the 2018 World Happiness Index, the best-known SWB global ranking. ${ }^{8}$ In descending order, the country fares worst on social support, healthy life expectancy, GDP per capita, generosity, freedom to make life choices, and perception of corruption.

As can be seen, Malagasy assess their well-being very poorly: only $9 \%$ of the listed countries had lower results. Moreover,

${ }^{6}$ The Education Index is one of the HDI's components and is measured by combining average adult years of schooling with the expected years of schooling for children, each receiving equal weighting.

${ }^{7}$ Salesians of Don Bosco and Salesian Sisters of Don Bosco are religious congregations that originated in Italy and are now working with the young and the poor in many countries, including Madagascar. in the 2013 Gallup survey, in which respondents are polled on how they perceive their well-being, Madagascar ranked 130th out of 135 countries. A mere $6 \%$ saw themselves as "thriving."

The objective indicators reveal that actual living conditions are likewise very poor. This situation is reflected in the second scenario in the previously mentioned methodology proposed by Michalos (2007), which states that "[i]f people's living conditions are bad, and people accurately perceive and think about them, feel bad, act appropriately but still with bad results, we may describe that as Real Hell."

\section{Methods}

This paper draws on the observations gathered by the FMB, a Polish NGO that has been granting scholarships to Malagasy youth since 2007, and, at time of writing, has supported 59 students from all over the island. The paper, therefore, explores the a posteriori knowledge drawn from the observations of FMB staff and the data collected through the Foundation's operations. The data used in this paper were taken from FMB annual summaries and reports. In addition to information stemming from the regular exchanges with students and the Malagasy volunteers who worked with the Foundation, a round of structured interviews was devised by the author and conducted by Foundation volunteers in 2018. The following questions were asked in French and translated into Malagasy:

Can you support your village now that you have graduated? What did your life look like before you began your studies, and how does it look now that you've graduated?

What do you do?

What was your favorite class?

What do you do now and what are your future plans? How many people go to university in Madagascar?

Has higher education helped you find a well-paid job?

What do you think is hindering Madagascar's development?

As SWB is a measure of individual well-being, it seems relevant to quote the voices of those whose lives are discussed in this paper. By no means, however, can this sample be regarded as representative. 


\section{Results}

Before the association between education and SWB in a low-income country can be discussed, the quotidian reality of that country needs to be understood. To this end, an illustrative day in the life of a Malagasy student is described in the following section. The theoretical terms (e.g. physical needs, education, psychological needs, well-being) used in this paper consequently find meaning in the context of a developing country. A theoretical model that attempts to explain the association between education and SWB in a developing country is then presented.

The pathway to education for a Malagasy student

Malagasy children and adolescents face many hurdles in gaining an education. There are differences in the pathways they take, depending on area (rural/urban), but the main difficulties are universal. The perspective here is that of a student from a modest background, usually rural or suburban. ${ }^{9}$ Readers interested in a broader analysis are directed to Venart and Reuter (2014).

In 2018, a Malagasy student spent an average of 6.1 years in school but was expected to complete 10.4 years of schooling. ${ }^{10}$ If Malagasy are driven to acquire education, it is not because it is an easy undertaking.

Both public and private schooling are based on the user pays principle. Public school students in remote areas feel the shortcomings of the system especially: teachers are often absent, unprepared, or even intoxicated in class. Students often commute several kilometers each way on foot, and school materials are scarce. The student/teacher ratio is almost $41: 1$ for primary, 20:1 for secondary, and a little over 24:1 for tertiary education (World Bank 2017). The government salary is neither stable nor sufficient to live on, forcing parents to donate money and/or food to teachers. The language of instruction at the primary level is standard Malagasy, but in remote rural areas children often speak a non-standard dialect at home, which can be a major learning inhibitor. There is little if any access to preschool preparation (recent studies (Walker et al. 2011; Heckman 2006) ascribe the higher success rate at higher levels of education to preschool preparation so it is worth noting that the number of preprimary students has grown 3 -fold: $12 \%$ in 2013 , skyrocketing to $37.5 \%$ in 2017). A child in school cannot help as much around the house or in the fields; this places a greater burden on the rest of the family. Moreover, school expenses, and having a student at home, translate into fewer eggs or fish in the family rice bowl, and, hence, a less nutritious diet. As for homework, primary school students are home around $2 \mathrm{pm}$, and, despite the heat, take advantage of the remaining daylight to help with the chores (e.g. washing clothes, preparing rice and cooking it on open fire, running errands, etc.). Night falls abruptly around $6 \mathrm{pm}$ (there are no long sunsets in Madagascar); therefore, a candle or, in rare cases (only $24 \%$ have access to electricity), a light bulb, is required for schoolwork. A candle or a higher electricity bill is, therefore, another costly educational expense. What is more, artificial light attracts mosquitos, so schoolwork needs to be done under a mosquito net - usually spread over a bed that the student shares with a younger sibling, and who is usually sleeping. Sunrise is around $6 \mathrm{am}$, but students are usually up before this, as they have to help with cooking rice for breakfast and need to leave early to get to school on time.

These sacrifices are made in the hope of a better life, especially in material terms. People are motivated by the universal expectation that a better education will bring more challenging, and hence better remunerated, employment. Unfortunately, this

${ }^{9}$ Roughly $80 \%$ of the population live in rural areas

${ }^{10} \mathrm{This}$ is the number of years of schooling that a child of school entrance age can expect to receive if prevailing patterns of age-specific enrolment rates persist throughout the child's life. Source: United Nations Development Programme. expectation is very seldom borne out. A job market structured like an inverted pyramid (8.5\% unemployment among people with higher education, $5 \%$ among people with intermediate education, and $1.1 \%$ among people with basic education), allpervasive corruption ( 2.5 out of 6 for transparency, accountability, and public sector corruption in the CPIA rating), and, as reported by FMB students, other barriers to entry, for example, ethnicity, all combine to make education a high-risk investment. The prospects for an educated young adult are not all that different from those of someone with little or no schooling.

Former FMB students interviewed in 2018

Students from Antsirabe and Betafo

One of the many who have taken a similar pathway is Student 1, aged 27, from Betafo. He graduated from a reputable university in Antsirabe with a Master's degree in law. ${ }^{11}$ He then went on to complete an internship in a public office, but has not been able to secure stable employment since. He explains that although there are jobs in Antsirabe they can only be obtained through bribery. The result is that young graduates lose out to people who can afford to pay bribes - regardless of educational qualifications or competence. They are, therefore, forced into temporary, low-paid jobs for which they are grossly overqualified. Apart from working in temporary jobs, Student 1 was helping his community with their legal affairs at the time of the interview. He found this a source of pride and satisfaction. Student 2, 29, states that education helped her "take her life in her own hands," and that young Malagasy "study in order to have a better life." Student 3,22 , declared that formal higher education "provides [him] with a living," even though he was working temporary jobs at the time of the interview. Student 4, in her twenties, was in the process of being admitted to a religious community and was already living with nuns.

\section{Students from Antananarivo}

Student 5, 28, was a straight-A student in high school. He was admitted to Ankatso, the best public university in the country, but dropped out after three years when an opportunity for stable employment at the airport came up. Student 6, 26, dropped out of university during his fourth year to take up an internship in the hope of improving his prospects. He spent three years trying to find a job, eventually worked at the airport for six years, and has been working two temporary jobs since 2019. He complains that companies only hire experienced people or family members. $\mathrm{He}$ is trying to emigrate to France, where some of his distant relatives live. Student 7, 27, despite having a master's degree, could not earn enough to support his family. After three years of temporary jobs, he now works in an accounting office.

\section{Other former FMB students' pathways}

More general observations are also applicable to the educational choices of the students. Betafo is a town of 32,000 and Fianarantsoa a city of 190,000 . Both are located in central regions and have large rural hinterlands. Their educational institutions draw their student bodies from the surrounding villages. The FMB students from these two areas mainly complete two-year vocational courses (e.g. hairdressing, dressmaking, administration). Toliara, Antananarivo (and suburban Ivato), and Mahajanga all have a major university, and students graduate with a BA or MA degree. Majors include accounting, management, Malagasy literature, veterinary medicine, English, computer science, obstetrics, tourism and hospitality, and agricultural engineering. Of the 59 students, 42 are women. This imbalance results from the fact that the vocational schools are girls-only institutions.

\footnotetext{
${ }^{11} \mathrm{Age}$ at the time of the interview
} 


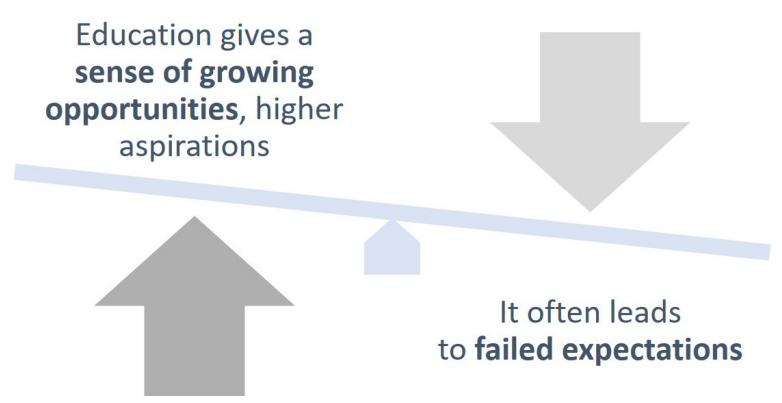

Figure 2. Education and SWB in developing countries. Negative association

Source: own elaboration

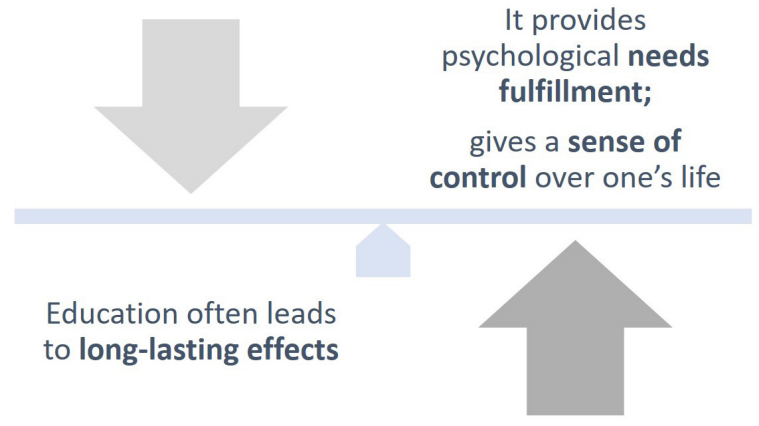

Figure 3. Education and SWB in developing countries. Positive association

Source: own elaboration

\section{Discussion}

The foregoing leaves little doubt that acquiring an education requires a tremendous amount of effort, as well as a considerable sacrifice of material needs on the part of the student and his/her family. This is mainly due to the incurred expenses and the extra workload imposed on the rest of the family when one or more children cannot help at home or in the fields. Consequently, once a family is brought to the basic needs threshold, SWB declines precipitously, as reported in Howell and Howell (2008). Students 1, 3,6 , and 7 , who have struggled for long periods to find stable employment, illustrate the downside of achieving a higher level of education.

This is an example of the failed expectations described by Kristoffersen, and is bound to lower the students' SWB. This is illustrated in Figure 2.
However, the brief student histories outlined above also illustrate a positive association between education and SWB. Student 1 stated that his status in the community is now higher, as he can help his relatives with their court and administrative cases. He is very proud that he can at least offer "moral support," as he calls it, and considers this an important accomplishment. Hence, his SWB has risen as a result of being of use to his family, which brings him a sense of fulfilment. This positive association is also evident with Students 2 and 3, who declared a greater self-confidence, and believe that their education has increased their prospects. Students 5, 6, and 7 eventually found positions that allowed them to make a living. This situation, presented in Figure 3 , not only results from an improvement in financial status (albeit not immediately and not to the expected level), but from having a sense of purpose, which translates into higher SWB.

This model describes the experience of students from rural and urban areas. Vocational schools equip their students with specific technical skills that they can employ back in their villages or in the city. University students, on the other hand, are more at the mercy of the market and have little choice but to seek employment in a large company or a government department. For this reason, the negative association illustrated in Figure 2 affects them more frequently and for longer periods.

\section{Conclusions}

The motivation for Malagasy students to acquire an education seems to be two-fold: (i) having their children educated fulfils their ambition to do their best for them and increases the family's social status, and (ii) perhaps most importantly, to exercise their "freedom to make life choices," to apply the designation used by the World Happiness Index. As stated in the García-Muñoz et al. study (2019), access to higher education plays "a more major role than political freedom or personal rights" in creating opportunities for a better life. We can conclude, then, that people choose to embark on the strenuous pathway to education because, in their eyes, it is the best and most affordable, way to shorten the odds of improving their lives.

This paper suffers from some obvious limitations. The sample of respondents is very small and is, therefore, only used for illustrative purposes. However, given the dearth of analyses on the subject, and the relatively long time span of the observations, it at least offers some insight into SWB and its association with education in Madagascar.

ORCID

Małgorzata Klein (D) https://orcid.org/0000-0003-3737-3591

\section{References}

Akyeampong, K Djangmah, J, Seidu A, Oduro, A \& Hunt, F. (2007) Access to Basic Education in Ghana: The Evidence and the Issues, CREATE Country Analytic Review, University of Sussex, Brighton

Botha, F 2014, 'Life satisfaction and education in South Africa: Investigating the role of attainment and the likelihood of education as a positional good', Social Indicators Research, vol. 118 , no. 2, pp. 555-578.

Clark, AE, Kamesaka, A \& Tamura, T 2015, 'Rising aspirations dampen satisfaction', Education Economics, vol. 23, no. 5 , pp. 515-531.

Diener, E, Oishi, S \& Lucas, RE 2009, 'Subjective well-being: The science of happiness and life satisfaction' in The Oxford Handbook of Positive Psychology, eds. SJ Lopez, CR
Snyder, E Diener, S Oishi \& RE Lucas, Oxford University Press, pp. 186-194.

García-Muñoz, TM, Milgram-Baleix, J \& Odeh-Odeh, O 2019, 'Inequality and life satisfaction in low- and Middle-Income Countries: The role of opportunity', Societies, vol. 9, no. 2, p. 37.

Gough, I \& McGregor, JA 2007, Wellbeing in developing countries: from theory to research, Cambridge University Press, Cambridge.

Heckman, JJ 2006, 'Skill formation and the economics of investing in disadvantaged children', Science, vol. 312, no 5782, pp. 1900-1902.

Helliwell, J, Layard, R \& Sachs, J 2019, World Happiness Report, Sustainable Development Solutions Network, New York. 
Howell, RT \& Howell, CJ 2008, 'The relation of economic status to subjective well-being in developing countries: a metaanalysis', Psychological Bulletin, vol. 134, no. 4, pp. 536560.

Jiménez, MD, Jiménez, FJ \& Caselles, JA 2014, ‘Education, job aspirations and subjective wellbeing: a quantile regression analysis'. Available from: <file:///C:/Users/micha/Downloads/ Dialnet-EducationJobAspirationsAndSubjectiveWellbei ng-5189080.pdf>. [10 March 2019].

Kristoffersen, I 2018, 'Great expectations: Education and subjective wellbeing', Journal of Economic Psychology, vol. 66, pp. 64-78.

Lopez, SJ, Snyder, CR, Diener, E, Oishi, S \& Lucas, RE (eds.) 2009, The Oxford handbook of positive psychology, Oxford University Press, New York.

Michalos, AC 2007, 'Education, Happiness and Wellbeing', Social Indicators Research, vol. 87, no. 3, pp. 347-366.

Nilsson, B 2019, 'The school-to-work transition in Developing Countries', The Journal of Development Studies, vol. 55, no. 5 , pp. 745-764.

Pettit, J \& White, S, 2004 Participatory approaches and the measurement of human well-being, UNU-WIDER, Helsinki.

Reyes-García, V, Babigumira, R, Pyhälä, A, Wunder, S, ZorondoRodríguez, F \& Angelsen, A 2016, 'Subjective wellbeing and income: Empirical patterns in the rural developing world', Journal of Happiness Studies, vol. 17, no. 2, pp. 773-791.

Rosling, H, Rosling, O \& Rosling Rönnlund, A 2018, Factfulness, Sceptre, London.

Ryan, RM \& Deci, EL 2000, 'Self-determination theory and the facilitation of intrinsic motivation, social development, and well-being', American Psychologist, vol. 55, no. 1, pp. 6878.

Stiglitz, JE 2010, The Stiglitz report. Reforming the international monetary and financial systems in the wake of the global crisis, The New Press, New York, London.

The World Bank Annual Report 2018 2018. Available from: <https://documents.worldbank.org/en/publication/ documents-reports/documentdetail/630671538158537244/ the-world-bank-annual-report-2018>. [10 March 2019].

Venart, L \& Reuter, K 2014, 'Education in Madagascar: A Guide on the state of the educational system, needed reforms and strategies for improvement', University of Mauritius Research Journal, no. 20, pp. 196-235.

Walker, SP, Wachs, TD, Grantham-McGregor, S, Black, MM, Nelson, CA, Huffman, SL, Baker-Henningham, H, Chang, SM, Hamadani, JD, Lozoff, B, Gardner, JMM, Powell, CA, Rahman, A \& Richter, L 2011, 'Inequality in early childhood: risk and protective factors for early child development', The Lancet, vol. 378, no. 9799, pp. 1325-1338. 